\title{
En un món emparaulat sempre som analfabets
}

\author{
Raquel Cercós (Universitat de Barcelona)
}

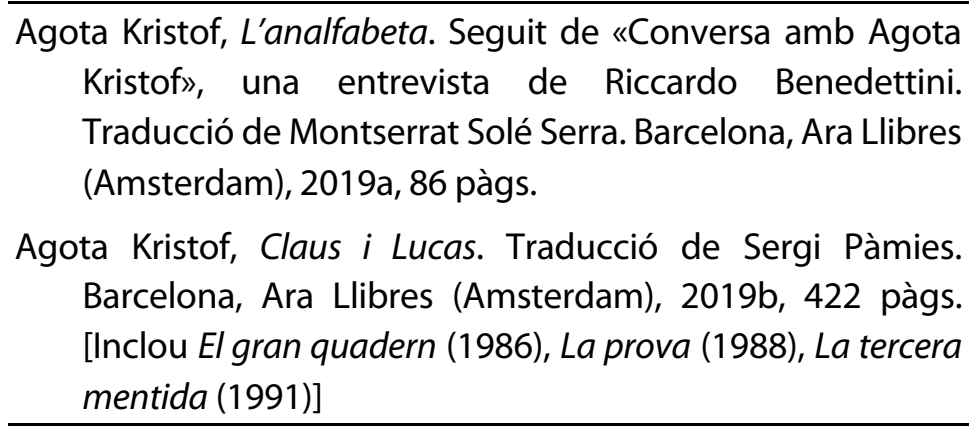

Fa uns anys el pare caputxí Jordi Llimona va escriure un llibre que va titular Sempre nòmades (1970). Llavors, en el rerefons, s'assistia a una polèmica entre aquells que defensaven les virtuts del sedentarisme i aquells altres que, com Llimona, advocaven per un món presidit pel nomadisme, una realitat que la globalització no ha fet més que corroborar. De fet, el nomadisme també té relació amb els exilis i les diàspores, amb els desterrats i perseguits, sempre presents en la història contemporània. De tal faisó que aquell llibre de Jordi Llimona ens ha inspirat el títol d'aquesta recensió bibliogràfica que constata que l'ésser humà viu en un món emparaulat, on es donen llengües i llenguatges, i que per raó del nomadisme dels trasllats -al món hi ha milions de persones desplaçades i refugiades- ens obliga a ser sempre analfabets. D'aquí l'interès de la breu narració L'analfabeta, de l'escriptora hongaresa Agota Kristof (1935-2011), una autora que va conèixer al final de la seva vida el reconeixement per la seva obra Claus i Lucas que reuneix la trilogia formada per El gran quadern (1986), La prova (1988) i La gran mentida (1991), Ilibres que s'han traduït a més de trenta llengües diferents.
És obvi que des d'una perspectiva pedagògica, ens interessa el joc de miralls que s'estableix entre L'analfabeta i El gran quadern, dues obres en què la nostra protagonista reflecteix molts episodis autobiogràfics, que es poden completar amb la lectura d'Ahir. De la seva trajectòria vital, cal ressaltar el període de la infància, que va coincidir amb els estralls de la Segona Guerra Mundial, sobretot pels esdeveniments que es van donar entre 1944 i 1945. No debades, la biografia d'Agota Kristof ens remet a la història recent d'Hongria que després d'aconseguir la independència de l'imperi austro-hongarès en el Tractat de Versalles (1920) -un pau cartaginesa, segons John Maynard Keynes- va ser dirigit pel règim autoritari de l'almirall Miklós Horty que, com a regent d'una monarquia sense rei, va governar el país entre 1920 i el 1944, quan va claudicar davant dels nazis, la qual cosa va provocar la invasió del país per les tropes de la Wehrmacht. En aquella conjuntura, Hongria es va convertir en un apèndix del III Reich amb el govern titella de Ferenc Szálasi, líder del Partit de les Creus Fletxades -els nazis hongaresos- que va desencadenar tot tipus de violències, amb una persecució sistemàtica de jueus entre 1944 i 1945. És ben conegut que llavors el Danubi-que 
Magris ha descrit amb els seus paisatgeses va transformar en un riu de dolor, atès que les víctimes de la repressió queien a les aigües tranquil.les pels trets dels assassins. El «monument de les sabates» que es va erigir el 2005 a la riba del riu és un testimoni colpidor d'aquelles atrocitats. S'ha dit que Budapest va esdevenir una ciutat màrtir que recorda els patiments que va sofrir Varsòvia, ciutats que van suportar la repressió nazi i els excessos de l'entrada soviètica.

No ens podem d'estar de notar que diferents autors (Sándor Márai, Arcadi Espada, etc.) han deixat constància d'aquell horror que va sacsejar la infància d'Agota Kristoff que va viure aquells anys a Köszeg, en una zona rural a tocar de la frontera amb Àustria, quan la mare es va quedar a la capital i el pare va anar al front. Allà, en aquella població, existia una important comunitat jueva que va ser la darrera que es va deportar a Auschwitz i també un camp de treball on van morir dotzenes de persones que, en els últims instants, va ser obligades a emprendre una de les marxes de la mort a banda de l'epidèmia de tifus que ja havia minvat la població reclosa. Per tant, Agota va veure com després de l'ocupació de les tropes germàniques, l'Exèrcit Roig va alliberar Hongria per imposar un règim totalitari que va practicar una política de russificació que va afectar el món educatiu. Naturalment, aquest doble procés - primer de germanització i més tard de russificació- va fer que Kristof, com la resta d'hongaresos, sofrissin el jou de les potències estrangeres, la qual cosa va determinar que a l'escola passessin en pocs anys d'estudiar l'alemany al rus, l'idioma de la nova ideologia hegemònica que havia imposat el Partit Comunista. Mentrestant, els hongaresos -que ja s'havien aixecat contra els austríacs en més d'una ocasió- van protagonitzar a la tardor de 1956 un moviment de revolta, en favor de la independència nacional que va comportar trenta mil morts, en ser sufocat pels tancs russos amb l'excusa de la signatura del Pacte de Varsòvia (1955).

Amb aquest panorama, Kristof va decidir fugir d'Hongria amb el seu espòs que era el seu professor d'història, i amb qui es va maridar quan tenia dinou anys, i una nena de quatre mesos, tot travessant clandestinament la frontera amb Àustria el 27 de novembre de 1956. Tot i que Amèrica era el destí buscat, Agota va iniciar una vida de refugiada que la va portar fins a Suïssa, a Neuchâtel, on va treballar en una fàbrica de rellotges, una feina mecànica que li permetia somniar amb la literatura, atès que escrivia des dels tretze anys. Ara bé, i davant la necessitat d'aprendre francès, Agota durant cinc anys no va poder llegir. «Cinc anys després de l'arribada a Suïssa, parlo francès, però encara no el llegeixo. Em converteixo en una analfabeta. Jo, que als quatre anys ja sabia llegir» (Kristof, 2019a, p. 58). A més, a Suïssa va començar a viure un desert social i cultural (Kristof, 2019a, p. 48), per bé que el francès fou per un atzar vital- la llengua que va convertir-la en una escriptora d'abast mundial. «A escriure en francès, hi estic obligada. És un repte. El repte d'una analfabeta» (Kristof, 2019a, p. 60). Per la pròpia dinàmica històrica, Kristof va arraconar un xic la llengua hongaresa, que al final de la seva vida parlava perfectament encara que l'escrivia amb algunes faltes (Kristof, 2019a, p. 72).

D'aquí ve que a través de la lectura dels llibres que comentem, ens conscienciem altra volta que vivim en un món emparaulat, circumstància de gran transcendència pedagògica, atès que com ha dit el professor Enric Prats, la literatura i la pedagogia segueixen vides paral.leles perquè «la bona literatura, a més de narració i màgia, conté una lliçó» (Prats, 2016, p. 13). 
Pròpiament, la literatura permet una comprensió o lectura pedagògica que pot contribuir, sense cap mena de dubte, a la formació humana. De resultes d'això, la pedagogia -que com diu el professor Prats- ha de «ser alguna cosa més que donar solucions al dia a dia: ha d'ajudar a pensar sobre l'educació» (Prats, 2016, p. 15), ha experimentat un gir narratiu, fins al punt que el seu basament teorètic no cal cercar-lo només en la filosofia -com molts pedagogs han expressat, des de Fichte i Dilthey a Alexandre Galí- sinó també en la literatura, una tendència que es va aguditzar quan els micro-relats van impugnar -Lyotard fou un dels apòstols d'aquest nou evangeli postmodern- les gras narratives, des del cristianisme al marxisme, que havien donat sentit a la història d'Occident. És absolutament obvi que aquest gir narratiu es fruit, al seu torn, d'altres dos girs, que s'impliquen mútuament i recíproca. Ens referim, com és lògic, al gir lingüístic que fou proclamat per la filosofia de Richard Rorty (The linguistic Turn, 1967) i pel gir hermenèutic que autors, com ara Hans-Georg Gadamer i Octavi Fullat, han aplicat a la pedagogia, tot proclamant que l'educació sempre significa un procés d'autoformació, inherent a la tradició de l'ideal formatiu (Bildung) de l'Alemanya neohumanista (1780-1830), una idea que d'una o altra manera també es pot trobar en el pensament d'Agota Kristof, però lluny de cercar l'ànima bella clàssica (Schiller).

Ben mirat, les històries d'Agota Kristof ens fan adonar de la importància del llenguatge, cosa que en el seu cas ve avalat pel fet que va viure a casa l'atmosfera dels rituals escolars perquè el seu pare era l'únic mestre del poble. Es pot afegir que l'estil de Kristof és dur i concís, sense barroquismes ni excessos. Tot és directe i punyent, i encara que a voltes sembla el reflex d'una realitat que és descrita sense més, darrera de les seves paraules s'amaguen les contradiccions de la condició humana i, molt especialment, la tragèdia d'Europa, és a dir, l'ensulsiada d'un continent que després de la contesa bèl-lica (1939-1945) va experimentar la Guerra Freda, amb tensions culturals $i$ ideològiques que van sotmetre nacions com Polònia, Txèquia i Hongria al dictat del sovietisme que encara avui és justificat, si més no indirectament a través d'un exercici d'empatia hermenèutica, per alguns historiadors que fan l'esforç de comprendre l'estalinisme (García Voltá, 2012). En aquest punt, podem afegir que Agota recorda com va viure a l'escola el dia de la mort de Stalin (1953), una prova palpable de l'adoctrinament ideològic que va acabar amb la creativitat del Iliure pensament.

De tal forma que resulta evident que I'analfabeta -personificada en Agota Kristof- dóna compte i raó sobre com va viure a l'Hongria bèl-lica quan el pare era al front, circumstància que la família va agrair pel seu caràcter autoritari, i la mare va romandre a la ciutat (hem de suposar que a Budapest). En aquest ambient, ella i el seu germà, es van transformar en unes petites feres salvatgines que vivien en la llar d'una àvia imaginària i feréstega que no coneixia els beneficis de la higiene i de la civilització i que, a més, no sabia llegir. S'ha de tenir en compte que la nostra autora sempre barreja la realitat i la ficció, si bé podem considerar que aquest estat de llibertat robinsoniana va permetre que Agota i el seu germà -que a Claus i Lucas són bessonsvisquessin unes històries sovint estranyes $i$, el que no és menys important, que practiquessin uns exercicis d'autodomini que van endurir el seu tremp, amb proves de dejuni, exercicis de ceguesa i sordesa, d'immobilitat fins arribar a extrems insospitats, amb algunes escenes certament cruentes, com la història del penjament del gat, i personatges marginals com la 
Llavi Partit amb la cara desfigurada. En aquestes proves, es detecta l'instint de supervivència i de defensa quan hom viu en unes circumstàncies hostils, amb el rerefons de la guerra, sense cap mena de seguretat i amb la presència a casa seva d'un oficial alemany.

No pot sorprendre, doncs, que algú com Agota, apassionada per la lectura i l'escriptura, recordi en les seves obres, sempre amb referències autobiogràfiques, els anys escolars. Ara bé, aquells anys escolars es van interrompre per causa de la guerra i els germans van optar per seguir un procés d'autoaprenentatge per anar a raure, finalment, a un internat de l'època soviètica en plena etapa estalinista. En aquest context, mots concrets com ara guix, tinta, paper, paper quadriculat, quadern, llapis, posen de relleu quins són els objectes que configuren un univers escolar que emfasitza la importància de la lectoescriptura. Al seu torn, aquest univers escolar necessita el complement d'altres escenaris com puguin ser papereries, Ilibreries, biblioteques públiques i privades, com la del mossèn del poble, per tal d'aconseguir llibres. Res d'estrany, doncs, que Kristof destaqui la importància de tres eines escolars bàsiques, a saber, la Bíblia, el Diccionari i el quadern escolar, a les quals en algun moment afegeix l'enciclopèdia.

\footnotetext{
Per als nostres estudis, tenim el diccionari del Pare i la Bíblia que hem trobat aquí, a casa de I'Àvia, a les golfes.
}

Fem Iliçons d'ortografia, de redacció, de lectura, de càlcul mental, de matemàtiques i exercicis de memòria.

Utilitzem el diccionari per a l'ortografia, per obtenir explicacions, però també per aprendre paraules noves, sinònims i antònims.

La Bíblia serveix per a la lectura en veu alta, per a dictats i per a exercicis de memòria. En conseqüència, aprenem pàgines senceres de la Bíblia (Kristof, 2019b, p. 36).
Com veiem, es tracta de tota una declaració formativa en què la Bíblia, el llibre que es va llegir intensivament durant segles, sobretot després de la Reforma luterana, ocupa una centralitat manifesta. Això vol dir que quan s'acabava es començava de nou, en Ilars on hi havia pocs llibres, i fins i tot on no tothom sabia llegir i escriure. De tal faisó que aquest univers escolar i cultural es converteix en la clau de volta d'un sistema d'autoaprenentatge que recorda el mètode de Jacotot, per bé que ambdós germans no partien del nores.

\begin{abstract}
Anem a l'escola durant dos anys i mig. Els mestres també se'n van al front; són substituïts per institutrius. Més endavant, l'escola tanca perquè hi ha massa alertes de bombardeigs.

Sabem llegir, escriure, comptar.

A casa de l'Àvia, decidim continuar els nostres estudis sense mestre, tots sols (Kristof, 2019b, p. 33).
\end{abstract}

Així les coses, i atès que vivim en un món emparaulat, la presència del diccionari es fa imprescindible, ja que constitueix una eina necessària per conèixer l'ortografia i el significat dels mots. I si bé això succeeix en qualsevol idioma, en el seu cas, encara va ser més peremptori pel que fa al francès. Al costat de la Bíblia i el diccionari, s'ha d'esmentar el quadern escolar, que dóna títol al primer llibre de la trilogia Claus i Lucas, noms ficticis d'Agota i del seu germà. En relació a aquest darrer punt, val a dir que Agota a l'institut escrivia un diari en hongarès, de manera que els objectes necessaris per l'estudi són ben definits. «Bíblia, diccionari, paper, llapis i el Gran Quadern on tot és escrit» (Kristof, 2019b, p. 106). En fi, aquests estris configuren una mena de fetitxisme per la lectura i l'escriptura, una mena d'obsessió que segueix Kristof des de la infància, una espècie de tresor que cal servar i conservar fins al darrer moment. No per atzar, en moltes cases 
es guarden encara avui els diccionaris escolars, algunes edicions de la Bíblia i, sobretot, quaderns escolars dels fills i néts. Com una veritable relíquia del passat.

D’aquí que Kristof descrigui un itinerari personal que va de la paraula a l'escriptura, amb episodis destacables com quan va ingressar en un internat els catorze anys, en un moment històric en què Hongria ja girava en l'òrbita soviètica. En efecte, convé consignar que en aquell moment, l'any 1949, els comunistes ja havien convertit Hongria en un país satèl-lit de I'URSS, fins al punt que l'educació en aquella conjuntura implicava un adoctrinament, a través dels llibres de «lectura obligatòria». Això establert, després de l'alliberament soviètic, la prioritat de les llengües també es va capgirar i el rus va ocupar un Iloc central. «A les escoles, la llengua dels nostres llibertadors és obligatòria, les altres llengües estrangeres estan prohibides» (Kristof, 2019b, p. 140). És fàcil entendre com Agota, encauada en un internat, va experimentar un estat de solitud, en romandre allunyada de la família, mentre el pare era a la presó. Així es va acabar la llibertat de moviments sota un règim escolar disciplinari mentre el fred tenallava els alumnes a l'aula. «A l'escola, ens traiem els abrics però cada quart d'hora ens aixequem per fer taules de gimnàstica per tornar a entrar en calor» (Kristof, 2019a, p. 20). I enmig de tot plegat, Agota - des d'una radical afirmació del seu jo- comença a escriure esquetxos després d'haver llegit molt, primer pas de les obres de teatre que escriurà a Suïssa.

Naturalment, en aquell internat que seguia les orientacions comunistes la llengua que s'havia imposat era el rus que així entrava en contradicció amb l'hongarès, una llengua uràlica que empra l'alfabet Ilatí i no el ciríl.lic. Potser caldria recordar que Hongria va ser un país cristianitzat, la qual cosa explica la importància de la Bíblia per la nostra autora que -es vulgui o no- es mou dins dels paràmetres de la cultura del Ilibre (García-Pelayo, 1997). Altrament, resulta del tot evident que vivim en un món emparaulat i les llengües Iluiten per imposar-se unes a les altres, alhora que es fa del tot impossible dominar tots els llenguatges, per la qual cosa sempre som doblement analfabets. Llevat d'això, no era la primera vegada que la nostra protagonista es va adonar que existien altres parles, perquè durant la seva infància havia escoltat els gitanos que eren estigmatitzats per la societat hongaresa i que van ser perseguits pels nazis. Tampoc s'ha de perdre de vista que Agota va viure a tocar d'Àustria, en la zona fronterera a Köszeg una realitat que emergeix en les històries de Claus i Lucas- on existia una minoria alemanya, de manera que era conscient que existien diversos idiomes, que a més no són neutres ni asèptics. Amb aquest enfocament, hi ha llengües enemigues com l'alemany, que des de l'època de l'imperi austríac havia estat imposada als hongaresos, tot i el compromís (Ausgleich) de 1867 que va donar lloc a la monarquia dual o bicèfala austrohongaresa. Si abans la llengua dominant era la germànica, ara s'imposava el rus que ningú coneixia, ni els mestres hongaresos que es van haver d'adaptar precipitadament gràcies a cursos accelerats. Des d'aquest prisma, la Unió Soviètica va exercir als ulls d'Agota una funció etnocida, perquè a banda $d^{\prime}$ 'imposar una economia planificada i una ortodòxia filosòfica, va intentar ofegar les cultures i les identitats nacionals dels diversos països (Kristof, 2019a, p. 33). És a dir, l'educació es va russificar no només lingüísticament sinó també pel que fa als continguts, en ser contaminats ideològicament, fins l'extrem d'afirmar que «de les escoles en surt una generació d'ignorants» (Kristof, 2019a, p. 29). 
Així als vint-i-un anys, el 1956, va arribar a Suïssa sense conèixer el francès, que primer va aprendre a parlar i, anys després, a escriure. Llavors es va sentir com si talment fos una rodamón, sense poder-se identificar en cap poble, de manera que va haver de sortir a la recerca del sentit d'una nova identitat en terra estranya i envoltada d'un llenguatge desconegut. Tal com ella reconeix, es trobava immersa en una mena de desert, en mig de grans dificultats econòmiques atès que a més s'havia separat del seu espòs, molt més gran que ella. Mentrestant, la situació dels hongaresos a l'estranger es feia insuportable i alguns retornaven malgrat les represàlies del règim comunista i altres es llevaven la vida. Així va ser testimoni de diversos suïcidis de gent propera. Amb tot, ella va lluitar fins convertir-se en una escriptora d'obres de teatre que es representaven en cafès i que es llegien en audicions radiofòniques, d'acord amb els esquetxos elaborats durant els anys d'escolaritat en l'internat. A banda, escriu un llibre que envia a tres editorials conegudes i, finalment, Seuil accepta publicar la trilogia Le grand cahier (1986), La preuve (1988) i Le troisième mensonge (1991) que conformen el volum de Claus i Lucas.

Tal vegada, un altre aspecte a tenir en compte estreba en considerar la distància que es dóna en la seva literatura entre la realitat i la ficció literària, entre la història i el somni oníric. Tant més quan sovint s'assisteix a una certa banalització de les paraules, com ella reconeix. «A força de repetir-les, les paraules perden a poc a poc el seu significat i el dolor que sentim s'atenua» (2019b, p. 31). Encara que no ens podem entretenir, convé fixar l'atenció en la qüestió de la veritat i la mentida, sempre en el Ilindar entre l'aparença i la realitat, perquè en darrera instància la veritat també esdevé una invenció a través de l'engany que els dos germans van practicar sovint i que Kristoff adopta com a tècnica narrativa a fi de crear uns imaginaris que cal desvetllar. Al capdavall, I'última obra de la trilogia es titula La tercera mentida, en un context en què la veritat es difumina com succeeix en el món postmodern en què el que més interessa és que les coses siguin versemblants, al marge de si són veritables o no. En l'entrevista amb Riccardo Benedettini reconeix que l'àvia és un personatge inventat, "però la seva feina no ho és» (Kristof, 2019a, p. 77). En la tergiversació sempre roman quelcom de real i així la línia de demarcació amb la realitat s'ha diluït fins fer-se intangible. S'ha d'afegir, a més, que en el món postmodern la frontera entre veritat i mentida, entre certesa i incertesa ja no existeix, perquè després de l'experiència dels totalitarismes probablement no hi ha cap fonament (Grund) sòlid que aguanti un món que s'ha fet líquid i en què Déu s'ha fet fonedís, més encara per una persona com Kristof que viu la descreença. En darrer terme, tot són paraules, només mots, que a força de repetir-los han perdut el seu significat original, la seva força primigènia. Potser val la pena, reproduir el següent fragment de La tercera mentida, quan Claus respon a Peter en relació a cinc quaderns escolars.

\footnotetext{
En Peter els obre un darrera l'altre:

-Realment tinc curiositat per saber què hi ha en aquests quaderns. És una mena de dietari, potser?

-No, són mentides.

-Mentides?

-Sí. Coses inventades. Històries que no són certes però que podrien ser-ho (Kristof, 2019b, p. 360).
}

Podem deduir que per Kristof el món no té un sentit transcendent, perquè la seva vida nòmada, d'hongaresa errant, la va convèncer que l'ésser humà sempre es troba en camí, en trànsit, talment com si es 
tractés d'un pelegrí, sense cap altra seguretat que el llenguatge que ens fa sempre analfabets perquè quan sembla que coneixem una llengua necessitem una altra. El somni esperantista del Dr. Zamenhoff, un jueu polonès que coneixia el rus, no és més que una quimera que ha estat impossible portar a la pràctica, llevat d'alguns cercles minoritaris com els llibertaris que propugnen un ideari internacionalista $\mathrm{i}$ pacifista. I encara que l'anglès ha esdevingut una nova koiné universal, el cert que vivim en un món curull de llengües i, nogensmenys, de llenguatges (filosòfic, polític, tècnic, icònic, gestual, etc.) que ens postra en una situació $d$ 'indigència permanent, d'analfabetisme evitern.

En suma, a la vista del que escriu Agota Kristof, la vida només té sentit gràcies a la lectura i a l'escriptura, mercès a la Bíblia i als diccionaris, als llapis i als quaderns escolars. Fem-hi un afegitó final. Per Kristof tampoc hi ha esperança escatològica de manera que allò que diu l'Evangeli de Joan que Déu s'ha fet Verb i Paraula, no és més que una altra ficció literària. Certament, en la literatura de Kristof es detecta un nihilisme que no és tràgic sinó vital, que sorgeix de les peripècies del segle $x x$. No obstant, per fer suportable aquest nihilisme comptem amb l'ajuda de la lectura i de l'escriptura, que així esdevenen dues tècniques de supervivència, més que simples teràpies, que a tot estirar ens podem ajudar a fer front al no sentit de la vida amb valentia i dignitat. Comptat i debatut, els éssers humans estem condemnats a ser uns analfabets impenitents que pelegrinem pel món a la recerca d'un sentit que, en els millors del casos, ens vindrà donat d'una manera emparaulada. No debades, Heidegger en la Carta sobre l'humanisme (1946), després de llegir poetes com Hölderlin, ja va afirmar que el llenguatge és la casa de l'ésser.

\section{Referències}

Espada, A. (2013) En nombre de Franco. Los héroes de la embajada de España en el Budapest nazi. Barcelona, Espasa.

Fullat, O. (2016) Impertinentes. El desgarro de pensar. Barcelona, Edicions de la Universitat de Barcelona.

Gadamer, H.-G. (2000) La educación es educarse. Barcelona, Paidós.

García-Pelayo, M. (1997) Las culturas del libro. Caracas, Fundación Manuel García-Pelayo.

García Voltá, G. (2012) Comprender el estalinismo. Ediciones Carena.

Kristof, A. (1996) Ahir. Barcelona, Edicions de la Magrana.

Kristof, A. (2015) La analfabeta. Relato autobiográfico. Pròleg de Josep Maria Nadal Suau. Madrid, Alpha Decay.

Prats, E. (2016) Aprendre de lletres. Literatura i pedagogia, vides paral.leles. Barcelona, Edicions Universitat de Barcelona.

Vilanou, C., Cercós, R. i de la Arada, R. (2017) «Pequeña rapsodia húngara. Las confesiones burguesas de Sándor Márai y otras narraciones de la vieja Europa». Ars Brevis, 23, p. 243-195. 